\title{
Pain, Mood, and Substance Abuse in HIV: Implications for Clinic Visit Utilization, ART Adherence, and Virologic Failure
}

\author{
Jessica S. Merlin, MD, MBA ${ }^{1,2}$, Andrew O. Westfall, MS ${ }^{1,3}$, James L. Raper, DSN, CRNP, \\ JD$^{1}$, Anne Zinski, PhD ${ }^{1}$, Wynne E. Norton, PhD ${ }^{4}$, James H. Willig, MD, MSPH ${ }^{1}$, Robert \\ Gross, MD, MSCE ${ }^{5}$, Christine S. Ritchie, MD, MSPH ${ }^{6}$, Michael S. Saag, MD ${ }^{1}$, and Michael J. \\ Mugavero, MD, MHSc ${ }^{1}$ \\ 1Division of Infectious Diseases, Department of Medicine, University of Alabama at Birmingham \\ ${ }^{2}$ Division of Gerontology, Geriatrics, and Palliative Care, Department of Medicine, University of \\ Alabama at Birmingham \\ ${ }^{3}$ Department of Biostatistics, School of Public Health, University of Alabama at Birmingham \\ ${ }^{4}$ Department of Health Behavior, School of Public Health, University of Alabama at Birmingham \\ ${ }^{5}$ Division of Infectious Diseases, Department of Medicine, Center for Clinical Epidemiology and \\ Biostatistics, University of Pennsylvania, and Philadelphia Veterans Affairs Medical Center, \\ Philadelphia, PA \\ ${ }^{6}$ Division of Geriatrics, Department of Medicine, University of California at San Francisco; Jewish \\ Home of San Francisco Center for Research on Aging
}

\section{Abstract}

\begin{abstract}
Introduction-Co-occurring pain, mood disorders, and substance abuse are common in HIVinfected patients. Our objective was to investigate the relationship between pain, alone and in the context of mood disorders and substance abuse, on clinic utilization, antiretroviral therapy (ART) adherence, and virologic suppression.
\end{abstract}

Methods-Pain, mood disorders, and substance abuse were assessed at the first visit. No-show and urgent visits were measured over a one-year period. Models were adjusted for age, race, sex, insurance status, CD4+ T-lymphocyte count, and HIV risk factor.

\begin{abstract}
Results-Among 1521 participants, 509 (34\%) reported pain, 239 (16\%) had pain alone, 189 $(13 \%)$ had pain and a mood disorder, and $30(2 \%)$ had pain and substance abuse. In univariate models, participants with pain, mood disorders, and substance abuse had higher odds of a no-show visit than participants without these conditions [OR 1.4 (95\% CI 1.1-1.8); OR 1.5 (95\% CI 1.21.9); OR 2.0 (95\% CI 1.4-2.8), respectively]. In the multivariable model, pain increased the odds of a no-show visit only in participants without substance abuse [OR 1.5 (95\% CI 1.1-1.9)], and pain reduced the odds of a no-show visit in participants with substance abuse [OR 0.5 (95\% CI $0.2-0.9)$, $\mathrm{p}$ for interaction $=0.0022]$.
\end{abstract}

Conclusions-In this study, pain increased the odds of no-show visits, but only for participants without substance abuse. Because pain, mood disorders, and substance abuse are highly prevalent in HIV-infected patients, our findings have implications for HIV treatment success. Interventions

Corresponding author: Jessica S. Merlin, MD, MBA, BBRB 222, $15303^{\text {rd }}$ Ave S, Birmingham, AL, 35294-2170, phone

215-806-1888, fax 205-934-5600, jmerlin@uab.edu.

Conflicts of Interest

For the remaining authors none were declared. 
that incorporate pain management may be important for improving health outcomes in patients living with HIV infection.

\section{Keywords}

HIV; Pain; Psychiatric Illness; Substance Abuse; ART Adherence; Health Care Utilization

\section{Introduction}

Clinically significant pain is common in patients with HIV infection. In a recent study of 154 ambulatory HIV-infected patients, $49 \%$ reported pain, of whom $51 \%$ had moderate to severe pain. ${ }^{1}$ Other studies in HIV-infected patients have estimated pain prevalence to be between 39 and $55 \% .^{2-7}$ Mood disorders and substance abuse are also common in patients with HIV infection. Prevalence estimates are as high as $41 \%$ for depression, $21 \%$ for anxiety, and $21 \%$ for substance abuse ${ }^{8-13}$ higher than observed in the general population. ${ }^{14,15}$ Moreover, patients with pain often suffer from mood disorders, especially depression and anxiety, and substance abuse. ${ }^{16}$ However, studies describing the cooccurrence of pain and mood disorders or substance abuse among persons living with HIV infection are lacking.

In the modern treatment era, patients with HIV infection who consistently take antiretroviral therapy (ART) can achieve sustained virologic suppression and a near-normal life expectancy. ${ }^{17}$ Thus, regular and consistent attendance at HIV primary care appointments (adherence to HIV primary care, or conversely, missed visits) ${ }^{18,19}$ and consistent administration of ART (adherence to ART) ${ }^{20-26}$ are of considerable importance across the HIV treatment cascade. ${ }^{27,28}$ Adherence to HIV primary care visits has been associated with lower mortality, ${ }^{18}$ and ART adherence has been associated with lower rates of virologic resistance, ${ }^{20}$ improved virologic outcomes, ${ }^{21,23}$ slower progression to AIDS, and improved survival. $24,26,9,13,29,30-35$ Notably, patients with mood disorders and substance abuse have twice the odds of poor adherence to ART than patients without these conditions, ${ }^{29,}{ }^{36-38}$ and patients with active substance abuse are half as likely to be adherent to HIV clinic visits. ${ }^{39}$

Despite the high prevalence of pain in HIV-infected patients, the impact of pain, alone and in the context of mood disorders and substance abuse, on clinic visit utilization (including no-show and urgent visits), adherence to ART, and ultimately, virologic failure, has not been well studied. Our objective was to test the hypothesis that pain is negatively related to these outcomes, and that these effects are accentuated by mood disorders and substance abuse.

\section{Methods}

\section{Study Participants}

The University of Alabama at Birmingham (UAB) 1917 Clinic Cohort is an ongoing prospective HIV clinical cohort protocol established in 1992 that has been described in detail previously (www.uabcliniccohort.org). ${ }^{40}$ The cohort includes 1976 patients actively engaged in primary HIV medical care at the UAB 1917 HIV/AIDS Clinic. Of these patients, 1705 have provided informed consent to complete electronic Patient Reported Outcome (PROs) questionnaires. ${ }^{40}$ PROs are standardized, validated, self-administered questionnaires that are integrated into routine clinical care. They are administered electronically to participants using touch screen computers at primary care visits every 4-6 months at UAB ${ }^{40,41}$ Implemented in April 2008, the PRO assessment includes instruments that span a variety of domains including mood disorders, substance abuse, and quality of life, which includes assessment of pain. The Cohort and this study were approved by the UAB IRB. 
Data were captured prospectively during the study period, between April 2008 and June 2011. Inclusion criteria for this study included HIV infection, speaking and reading English, age $\geq 19$ years at the date of the first completed PRO questionnaire during the study period, and having at least one year of follow-up until the end of the study period or death. Data from PRO questionnaires, the administrative scheduling system (IDX), the 1917 Clinic electronic medical record, and the 1917 Clinic Cohort electronic database were used to obtain values for independent variables, outcome variables, and covariates.

\section{Independent Variables}

Pain, mood disorders, and substance abuse were the principal independent variables of interest and were measured at the first visit during the study period during which a PRO questionnaire was completed, referred to as the index visit. Pain was measured using the EuroQOL, which includes a single question about pain "today." Participants' responses to this question were dichotomized as moderate/extreme discomfort versus no pain/ discomfort. ${ }^{42}$ A mood disorder was defined as the presence of either depression, anxiety, or both. Participants with moderate, moderately severe, and severe depressive symptoms (PHQ-9>10) were considered to be depressed. ${ }^{43,44}$ Participants with anxiety symptoms and panic syndrome (PHQ-A $>1$ ) were considered to have anxiety. ${ }^{45}$ Substance abuse was measured using the ASSIST questionnaire and categorized as current or prior/never. ${ }^{46}$

\section{Outcome Variables}

We studied 4 outcomes: 1) no-show visits, 2) urgent visits, 3) adherence to ART, and 4) virologic suppression. No-shows and urgent care visits were measured over a one year observation period following the index visit, and adherence and virologic suppression were measured at the index visit. ART adherence was measured using the AACTG questionnaire among participants who reported being on ART. ${ }^{47}$ Based upon recent guidelines that suggest patients should be asked to recall their adherence over a relatively short timeframe, ${ }^{48}$ evidence that suggests adherence in the low $90 \%$ range can adversely affect outcomes, ${ }^{49-50}$ and prior studies that have used this approach, ${ }^{51}$ participants who reported missing ART medications within the past 2 weeks were considered to have suboptimal adherence. Virologic failure was defined as an HIV viral load $\geq 200$ copies $/ \mathrm{mL}$ among participants who reported being on ART, in accordance with current guidelines. ${ }^{52}$ Standard of care at the site included HIV primary care visits scheduled every three to six months. Urgent care visits are available on weekdays to patients with any pressing medical issue, and are scheduled by a triage nurse. Having at least one no-show visit over one year has been associated with increased mortality in multiple settings. ${ }^{53-55}$ Consistent with prior studies, ${ }^{56}$ no-show visits were defined as scheduled HIV primary care visits the patient did not attend and did not call ahead to cancel. Individuals having any no-show primary HIV provider or having any urgent care visits for the year were considered to have met these dichotomized endpoints.

\section{Covariates}

Covariates were selected from a list of numerous potential covariates, including age, race, sex, insurance status, CD4+ T-lymphocyte count, HIV transmission risk factor, and body mass index. Only body mass index was not consistently associated with our outcomes of interest; therefore, we included the remainder of the covariates in our models.

\section{Statistical Analyses}

Separate univariate and multivariable logistic regression models were built for each outcome. We first analyzed the main effects of pain, mood, and substance abuse on outcomes. Then, we evaluated the two and three way interactions between pain, mood, and 
substance abuse. These interaction terms formally assess whether the effect of pain, mood, and substance differ in the presence of the other. When the p-value for the interaction was $<0.2$, we reviewed the consistency of the point estimates of the main effects and interaction models to determine whether the results should be stratified. When the p-value for the interaction was $>0.2$ or when the point estimates were similar, we only considered the main effects.

Based on prior analyses from this cohort demonstrating interactions between race and sex, (reference here) we stratified race and sex into four-categories: non-white female, non-white male, white female, white male.

\section{Results}

As of the index date, participants had a median age of 44 years and were predominantly male, uninsured or had public insurance, had CD4+ T-lymphocyte counts $>350$ cells $/ \mathrm{mL}$, and were virologically suppressed (Table 1). Pain was common, occurring in $34 \%$ of participants. Mood disorders occurred in $25 \%$ of participants, and substance abuse occurred in $10 \%$. Pain, mood disorders, and substance abuse commonly co-occurred. In addition, of the of the 376 patients who reported moderate or extreme pain at the first PRO in the study period and who had a subsequent pain value in the study period, 255 (67.8\%) again reported moderate or extreme pain.

\section{No-show visits}

In univariate models, participants with pain, mood disorders, and substance abuse had higher odds of a no-show visit than participants without these conditions [OR 1.4 (95\% CI 1.11.8); OR 1.5 (95\% CI 1.2-1.9); OR 2.0 (95\% CI 1.4-2.8), respectively]. There was a significant interaction between pain and substance abuse. In the multivariable model, pain increased the odds of a no-show visit only in participants without substance abuse [OR 1.5 (95\% CI 1.1-1.9)], and pain reduced the odds of a no-show visit in participants with substance abuse [OR 0.5 (95\% CI 0.2-0.9), p for interaction=0.0022]. Similarly, substance abuse increased the odds of a no-show visit only in participants without pain [OR 3.1 (95\% CI 1.8-5.3)]; for participants with pain, substance abuse had no impact on the odds of a noshow visit [OR $0.9,(95 \%$ CI $0.6-1.6)$, p value for interaction $=0.0022]$. In the multivariable model, being a non-white female, non-white male, or white female, lack of insurance or public insurance, and a CD4 count of $<200$ or 200-350 cells $/ \mathrm{mL}$ were also associated with higher odds of having at least 1 no-show. In contrast, increasing age was inversely associated with having a no-show.

\section{Urgent Visits}

Participants with mood disorders had higher odds of an urgent visit than participants without mood disorders [unadjusted OR 1.8 (95\% CI 1.4-2.4); adjusted OR 1.6 (95\% CI 1.2-2.2)]. The relationship between pain and having an urgent visit was present in the unadjusted model [OR 1.6 (95\% CI 1.2-2.0)] but only marginal in the adjusted model [OR 1.3 (95\% CI 1.0-1.7)]. Substance abuse was not related to urgent visits in either the adjusted or unadjusted model. There was no evidence of interactions between pain, mood disorders, or substance abuse. In the multivariable model, having public insurance or a CD4 count of $200-350$ cells $/ \mathrm{mm}^{3}$ were also associated with having an urgent visit.

\section{ART Adherence}

Participants with mood disorders and substance abuse had higher odds of suboptimal ART adherence than participants without these disorders [unadjusted OR 2.1 (95\% CI 1.6-2.9) and adjusted OR 2.2 (95\% CI 1.5-3.2); adjusted OR 3.1 (95\% CI 2.0-4.8) and adjusted OR 
2.8 (95\% CI 1.7-4.6) respectively]. The relationship between pain and adherence was small in the unadjusted model [OR 1.4, (95\% CI 1.1-1.9] and absent in the adjusted model [OR 1.2 (95\% CI 0.8-1.7]. There was no evidence of interaction between pain, mood disorders, or substance abuse. In the multivariable model, being a non-white female, non-white male, or white female was also associated with suboptimal ART adherence.

\section{Virologic failure (viral load $\geq 200 \mathrm{c} / \mathrm{mL}$ )}

There was no relationship between pain, mood, or substance abuse and virologic failure [unadjusted OR 1.2 (95\% CI 0.9-1.5) and adjusted OR 1.1 (95\% CI 0.8-1.5); unadjusted OR 1.2 (95\% CI 0.9-1.7) and adjusted OR 1.1 (95\% CI 0.8-1.6); unadjusted OR 1.4 (95\% CI 0.9-2.1) and adjusted OR 1.1 (95\% CI 0.7-1.8)]. There was no evidence of interaction between pain, mood disorders, or substance abuse. In the multivariable model, being a nonwhite male, having a CD4+ T-cell count $<200$, and having a CD4+ T-cell count between $200-350$ cells $/ \mathrm{mm}^{3}$ were associated with virologic failure.

\section{Discussion}

In our study, pain increased the odds of no-show visits, but only for participants without substance abuse. In the subset of participants with substance abuse, who are traditionally difficult to retain in HIV primary care, pain actually appeared to be protective against noshow visits. By affecting no-show visits, an important step in the HIV treatment cascade, pain has important implications for individual and public health outcomes. No shows are a marker of retention in HIV primary care, ${ }^{56}$ and the importance of retention in HIV primary care has been increasingly recognized. Retention is prominently featured in recent HIV guidelines $^{48}$ and in the US National HIV/AIDS Strategy. ${ }^{57}$

There are numerous potential explanations for our findings about the relationship of pain to no-show visits. In patients without substance abuse, pain increases the risk of a no-show. We hypothesized that pain would negatively affect no-show visits, as patients with pain may feel too sick to come to an HIV primary care visit, or prioritize HIV primary care lower than pain relief, which they can achieve outside the context of an HIV primary care visit. However, we found the opposite: patients with substance abuse are actually more likely to attend an HIV primary care visit if they have pain. It is possible that patients with substance abuse may have more severe and difficult to control pain, as prior substance use may be associated with increased pain severity. ${ }^{58}$ As a result, patients with a history of substance abuse may be more likely to keep their HIV primary care appointments because they plan to seek help for their pain from their HIV primary care provider. If opioids are prescribed for pain, this may necessitate a clinic visit, as many opioid prescriptions cannot be called into pharmacies. The mechanism behind these complex associations between pain, substance abuse, and no-show visits should be investigated, as it has potential to be used in retention interventions for patients with pain, with and without substance abuse. Such interventions would likely require multidisciplinary and multifaceted components to address patients' pain and substance abuse.

It is unclear whether the pain patients report in this study is acute or chronic. While we did not specifically ask participants about chronic pain, we found that of the 376 patients who reported moderate or extreme pain at the first PRO in the study period and who had a subsequent pain value in the study period, $255(67.8 \%)$ again reported moderate or extreme pain. This suggests that these patients may have chronic pain. The strongest evidence for effective chronic pain management comes from interdisciplinary approaches that incorporate physical rehabilitation and psychological therapies, in addition to pharmacologic management. ${ }^{59}$ Recent evidence suggests that HIV primary care providers often use opioids to manage chronic pain, ${ }^{60}$ and often feel uncomfortable and inadequately trained to do so. ${ }^{61}$ 
HIV providers and clinics need to be able to access additional resources, either within their clinic or in the larger local community, to address the pain needs of their patients.

This study is one of many studies that confirm the high prevalence of pain among patients with HIV.${ }^{1-4}$ In addition, this study is the first to examine pain's downstream effects. Many other conditions, such as the metabolic syndrome and renal disease, are prevalent in patients with HIV, have negative downstream effects, and as a result, have been identified as important targets of early treatment. ${ }^{52}$ We posit that pain's protective effect against no-show visits also makes it an important target for investigation. The effect of treating pain, in particular in patients with substance abuse, is unclear. As pain is protective against no shows, it is possible that improving patients' pain could result in more no-shows. This does not undermine the need to treat pain, but rather, draws attention to the importance of doing so in a way that does not have unintended consequences. Research into evidence-based approaches to pain management in patients with HIV is lacking.

Consistent with prior results, we also found that mood disorders and substance abuse were associated with worse outcomes. Mood disorders were associated with higher odds of an urgent visit, both mood disorders and substance abuse were associated with higher odds of suboptimal adherence, and substance abuse was associated with higher odds of no-show visits in participants without pain. Development of pain-based interventions must explore the substantial impact of mood disorders and substance abuse, and consider the importance of these conditions as part of the intervention. Furthermore, in our multivariable analyses, younger age, being non-white, no insurance or public insurance, and lower CD4 counts were associated with worse outcomes. This is consistent with prior findings regarding retention ${ }^{18}$ and adherence ${ }^{62}$ in HIV-infected patients, highlighting the importance of these behaviors as contributors to health care disparities in HIV outcomes.

This study has limitations. The EuroQOL questionnaire assessed pain "today," and did not distinguish between acute pain, such as pain related to recent injury, chronic pain, which is defined as persistent pain that lasts longer than 3 months. ${ }^{63-66}$ Future prospective studies should capture data to differentiate and specifically evaluate the role of chronic pain in HIVrelated outcomes. In addition, this study does not address issues of causality or the mechanisms by which pain, mood disorders, and substance abuse affect outcomes. Future studies using quantitative and qualitative means should explore the mechanisms by which these associations occur. These studies may provide insight into how to develop interventions to improve engagement in HIV primary care in patients with HIV and pain.

Because pain, mood disorders, and substance abuse are highly prevalent in HIV-infected patients, our findings have implications for HIV treatment success. Our findings suggest that interventions that incorporate pain management should be investigated, as they may be important for improving health outcomes in patients living with HIV infection.

\section{Acknowledgments}

We thank the University of Alabama at Birmingham 1917 Clinic Cohort Observational Database Project team and the Research and Informatics Service Center for their assistance with this study.

\footnotetext{
Sources of Funding: AW has received consulting fees from Definicaire LLC. RG is supported by the Penn Center for AIDS Research (CFAR) (P30 AI 045008). CSR is supported by 7K07AG031779 (NIA). MJM is supported by K23MH082641 and has received consulting fees (advisory board) from Merck Foundation, Bristol-Myers Squibb, and Gilead Sciences, and grant support to UAB from Tibotec Therapeutics, Pfizer, Inc, Bristol-Myers Squibb, and Definicare, LLC.
} 


\section{References}

1. Merlin JS, Cen L, Praestgaard A, et al. Pain and Physical and Psychological Symptoms in Ambulatory HIV Patients in the Current Treatment Era. J Pain Symptom Manage. 2011 Nov 22. [Epub ahead of print].

2. Newshan G, Bennett J, Holman S. Pain and other symptoms in ambulatory HIV patients in the age of highly active antiretroviral therapy. J Assoc Nurses AIDS Care. 2002; 13(4):78-83. [PubMed: 12149887]

3. Harding R, Molloy T, Easterbrook T, et al. Is antiretroviral therapy associated with symptom prevalence and burden? Int J STD AIDS. 2006; 17:400-5. [PubMed: 16734963]

4. Silverberg MJ, Gore ME, French AL, et al. Prevalence of clinical symptoms associated with Highly Active Antiretroviral Therapy in the Women's Interagency HIV Study. Clin Infect Dis. 2004; 39:717-24. [PubMed: 15356788]

5. Cervia LD, McGowan JP, Weseley AJ. Clinical and demographic variables related to pain in HIVinfected individuals treated with effective, combination antiretroviral therapy (cART). Pain Med. 2010; 11(4):498-503. [PubMed: 20210870]

6. Lee KA, Gay C, Portillo CJ. Symptom experience in HIV-infected adults: a function of demographic and clinical characteristics. J Pain Symptom Manage. 2009; 38(6):882-93. [PubMed: 19811886]

7. Harding R, Lampe FC, Norwood S, et al. Symptoms are highly prevalent among HIV outpatients and associated with poor adherence and unprotected sexual intercourse. Sex Transm Infect. 2010; 86:520-24. [PubMed: 20551235]

8. Pence BW, Miller WC, Whetten K, et al. Prevalence of DSM-IV-defined mood, anxiety, and substance use disorders in an HIV clinic in the Southeastern United States. J Acquir Immune Defic Syndr. 2006; 42:298-306. [PubMed: 16639343]

9. DeLorenze GN, Satre DD, Quesenberry CP, et al. Mortality after diagnosis of psychiatric disorders and co-occuring substance use disorders among HIV-infected patients. AIDS Patient Care STDs. 2010; 24(11):705-712. [PubMed: 20969465]

10. Gaynes BN, Pence BW, Eron JJ. Prevalence and comorbidity of psychiatric diagnoses based on reference standard in an HIV+ patient population. Psychosomatic Med. 2008; 70:505-511.

11. Nurutdinova D, Chrusciel T, Zeringue A, et al. Mental health disorders and the risk of AIDSdefining illness and death in HIV-infected veterans. AIDS. 2011 [Epub ahead of print].

12. Orlando M, Burnam MA, Beckman R, et al. Re-estimating the prevalence of psychiatric disorders in a nationally representative sample of persons receiving care for HIV: results from the HIV Cost and Services Utilization Study. Int J Methods Psych Res. 2006; 11(2):75-82.

13. Galvan FH, Burnam MA, Bing EG. Cooccurring psychiatric symptoms and drug dependence or heavy drinking among HIV-positive people. J Psychoactive Drugs. 2003; 35(Suppl 1):153-160. [PubMed: 12825758]

14. Manchikanti L, Cash CA, Damron KS, et al. Controlled substance abuse and illicit drug use in chronic pain patients: an evaluation of multiple variables. Pain Physician. 2006; 9:215-226. [PubMed: 16886030]

15. Morasco BJ, Gritzner, Lewis L, et al. Systematic review of prevalence, correlates, and treatment outcomes for chronic non-cancer pain in patients with comorbid substance use disorder. Pain. 2011; 152(3):488-97. [PubMed: 21185119]

16. Fishbain DA. Approaches to treatment decisions for psychiatric comorbidity in the management of the chronic pain patient. Med Clin N America. 1999; 83(3):737-760. [PubMed: 10386123]

17. Antiretroviral Therapy Cohort Collaboration. Life expectancy of individuals on combination antiretroviral therapy in high-income countries: a collaborative analysis of 14 cohort studies. Lancet. 2008; 372:293-9. [PubMed: 18657708]

18. Mugavero MJ, et al. Missed visits and mortality among patients establishing initial outpatient HIV treatment. Clin Infect Dis. 2009; 48:248-56. [PubMed: 19072715]

19. Mugavero MJ, Lin H, Willig JH, et al. Early retention in HIV care and viral load suppression: implications for a test and treat approach to HIV prevention. J Acquir Immune Def Syndr. 2011 Sep 20. [Epub ahead of print]. 
20. Paterson DL, Swindells S, Mohr J, et al. Adherence to protease inhibitor therapy and outcomes in patients with HIV infection. Ann Intern Med. 2000; 133:21-30. [PubMed: 10877736]

21. Gross R, Bilker WB, Friedman HM, et al. Effects of adherence to newly initiated antiretroviral therapy on plasma viral load. AIDS. 2001; 15:2109-2117. [PubMed: 11684930]

22. Press N, Tyndall MW, Wood E, et al. Virologic and immunologic response, clinical progression, and highly active antiretroviral therapy adherence. JAIDS. 2002; 31:S112-S117. [PubMed: 12562032]

23. Hogg RS, Heath K, Bangsberg D, et al. Intermittent use of triple-combination therapy is predictive of mortality at baseline and after 1 year of follow-up. AIDS. 2002; 16:1051-8. [PubMed: 11953472]

24. Bangsberg DR, Perry S, Charlebois ED, et al. Adherence to HAART predicts progression to AIDS. AIDS. 2001; 15:1181-3. [PubMed: 11416722]

25. Garcia de Olalla P, Knobel H, Carmona A, et al. Impact of adherence and highly active antiretroviral therapy on survival in HIV-infected patients. J Acquir Immune Defic Syndr. 2002; 30:105-110. [PubMed: 12048370]

26. Gross R, Yip B, Lo Re V III, et al. A simple, dynamic measure of antiretroviral therapy adherence predicts failure to maintain HIV-1 suppression. Infect Dis. 2006; 194(8):1108-1114.

27. Aberg JA, Kaplan JE, Libman H, et al. Primary care guidelines for the management of persons infected with human immunodeficiency virus: 2009 update by the HIV medicine Association of the Infectious Diseases Society of America. Clin Infect Dis. 2009; 49(5):651-681. [PubMed: 19640227]

28. Gardner EM, McLees MP, Steiner JF, et al. The spectrum of engagement in HIV care and its relevance to test-and-treat strategies for prevention of HIV infection. Clin Infect Dis. 2011; 52(6): 793-800. [PubMed: 21367734]

29. Gordillo V, del Amo J, Soriano V, et al. Sociodemographic and psychological variables influencing adherence to antiretroviral therapy. AIDS. 1999; 13:1763-1769. [PubMed: 10509579]

30. Leserman J. Role of depression, stress, and trauma in HIV disease progression. Psychosom Med. 2008; 70:539-545. [PubMed: 18519880]

31. Ironson G, O'Cleirigh C, Fletcher MA, et al. Psychosocial factors predict CD4 and viral load change in men and women with human immunodeficiency virus in the era of highly active antiretroviral treatment. Psychosom Med. 2005; 67:1013-1021. [PubMed: 16314608]

32. Ickovics JR, Hamburger ME, Vlahov D, et al. Mortality, CD4 cell count decline, and depressive symptoms among HIV-seropositive women: longitudinal analysis from the HIV Epidemiology Research Study. JAMA. 2001; 285:1466-1474. [PubMed: 11255423]

33. Wagner GJ, Goggin K, Remien RH, et al. A closer look at depression and its relationship to HIV antiretroviral adherence. Ann Behav Med. 2011; 42(3):352-60. [PubMed: 21818528]

34. Lucas GM, Griswold M, Gebo KA, et al. llicit drug use and HIV-1 disease progression: A longitudinal study in the era of highly active antiretroviral therapy. Am J Epidemiol. 2006; 163:412-420. [PubMed: 16394200]

35. Pence BW. The impact of mental health and traumatic life experiences on antiretroviral treatment outcomes for people living with HIV/AIDS. J Antimicrob Chemo. 2009; 63:636-40.

36. Gonzalez JS, Batchelder AW, Psaros C, et al. Depression and HIV/AIDS treatment nonadherence: a review and meta-analysis. J Acquir Immune Defic Syndr. 2011; 58:181-187. [PubMed: 21857529]

37. Mellins CA, Havins JF, McDonnell C, et al. Adherence to antiretroviral medications and medical care in HIV-infected adults diagnosed with mental and substance abuse disorders. AIDS Care. 2009; 21(2):168-177. [PubMed: 19229685]

38. Carrico AW, Riley ED, Johnson MO, et al. Psychiatric risk factors for HIV disease progression: the role of inconsistent patterns of antiretroviral therapy utilization. J Acquir Immune Defic Syndr. 2011; 56(2):146-150. [PubMed: 21116186]

39. Marx KA, Malka ES, Ravishankar J, et al. Measurement of retention among adults infected with HIV in an urban clinic. AIDS Care. 2011; 23(10):1298-304. [PubMed: 21939407]

40. Kozak MS, Mugavero MJ, Ye J, et al. Patient reported outcomes in routine care: advancing data capture for HIV cohort research. Clin Infect Dis. 2011 Epub ahead of print. 
41. Crane HM, Lober W, Webster E, et al. Routine collection of patient-reported outcomes in an HIV clinic setting: the first 100 patients. Current HIV research. 2007; 5(1):109-18. [PubMed: 17266562]

42. EuroQOL. [Last accessed January 6, 2012] http://www.euroqol.org/

43. Spitzer RL, Kroenke K, Williams JB. Validation and utility of a self-report version of PRIME-MD: the PHQ primary care study. Primary Care Evaluation of Mental Disorders. Patient Health Questionnaire. JAMA. 1999; 282(18):1737-1744. [PubMed: 10568646]

44. Kroenke K, Spitzer RL, Williams JB. The PHQ-9: validity of a brief depression severity measure. J Gen Intern Med. 2001; 16(9):606-613. [PubMed: 11556941]

45. Lowe B, Grafe K, Zipfel S, et al. Detecting panic disorder in medical and psychosomatic outpatients: comparative validation of the Hospital Anxiety and Depression Scale, the Patient Health Questionnaire, a screening question, and physicians' diagnosis. J Psychosom Res. 2003; 55(6):515-519. [PubMed: 14642981]

46. Humeniuk R, Ali R, Babor TF, et al. Validation of the alcohol, smoking, and substance abuse involvement screening test (ASSIST). Addiction. 2008; 103(6):1039-47. [PubMed: 18373724]

47. Buscher A, Hartman C, Kallen MA, et al. Validity of self-report measures in assessing antiretroviral adherence of newly diagnosed, HAART naïve, HIV patients. HIV Clin Trials. 2011; 12(5):244-54. [PubMed: 22180522]

48. Thompson MA, Mugavero MJ, Amico R, et al. Guidelines for improving entry into and retention in care and antiretroviral adherence for persons with HIV: Evidence-based recommendations from an international association of physicians in AIDS care panel. Ann Intern Med. 2012 Mar 5. [epub ahead of print].

49. Bisson GP, Rowh A, Weinstein R, et al. Antiretroviral failure despite high levels of adherence: discordant adherence-response relationship in Botswana. J Acquir Immune Defic Syndr. 2008; 49(1):107-10. [PubMed: 18667926]

50. Gross R, Yip B, Lo Re V 3rd, et al. A simple, dynamic measure of antiretroviral therapy adherence predicts failure to maintain HIV-1 suppression. J Infect Dis. 2006; 194(8):1108-14. [PubMed: 16991085]

51. Kozak MS, Mugavero MJ, Ye J, et al. Patient reported outcomes in routine care: advancing data capture for HIV cohort research. Clin Infect Dis. 2012; 54(1):141-7. [PubMed: 22042879]

52. US Department of Health and Human Services. [Last accessed March 12, 2012] Guidelines for the use of antiretroviral agents in HIV-1 infected adults and adolescents. http://www.aidsinfo.nih.gov/ contentfiles/adultandadolescentgl.pdf

53. Mugavero MJ, et al. Missed visits and mortality among patients establishing initial outpatient HIV treatment. Clin Infect Dis. 2009; 48:248-56. [PubMed: 19072715]

54. Horberg, M.; Hurley, L.; Klein, D., et al. Early missed visits post-HIV diagnosis and Mortality in a Large Healthcare System. Poster presentation. Conference on Retroviruses and Opportunistic Infections; 2012; Seattle, WA.

55. Zhang Y, Dou Z, Sun K, et al. Association between missed early visits and mortality among patients of China national free antiretroviral treatment cohort. J Acquir Immun Defic Syndr. 2012; 1:60(1):59-67.

56. Mugavero MJ, Davila JA, Nevin CR, et al. From access to engagement: measuring retention in outpatient HIV care. AIDS Patient Care STDs. 2010; 24 (10):607-13. [PubMed: 20858055]

57. Eldred L, Malitz F. Introduction [to the supplemental issue on the HRSA SPNS Outreach Initiative]. AIDS Patient Care STDS. 2007; 21 (Suppl 1):S1-S2.

58. Compton P, Charuvastra VC, Kintaudi K, et al. Pain responses in methadone-maintained opioid abusers. J Pain Sympotm Manage. 1999; 20(4):237-45.

59. Clark ME, Hooten WM, Sanders SH. Interdisciplinary pain rehabilitation: current challenges and future opportunities. Pain Med. 2011; 12(1):152-3. [PubMed: 21223493]

60. Onen NF, Barrette EP, Shacham E, et al. A review of opioid prescribing practices and associations with repeat opioid prescriptions in a contemporary HIV outpatient clinic. Pain Pract. 2011 Nov 22. [Epub ahead of print]. 
61. Lum PJ, Little S, Botsko M, et al. Opioid-prescribing practices and provider confidence recognizing opioid analgesic abuse in HIV primary care settings. J Acquir Immune Defic Syndr. 2011; 56 (Suppl 1):S91-97. [PubMed: 21317601]

62. Halkitis P, Palamar J, Mukherjee P. Analysis of HIV medication adherence on relation to person and treatment characteristics using hierarchical linear modeling. AIDS Patient Care STDs. 2008; 22(4):323-25. [PubMed: 18290734]

63. Adler RH. The term "chronic" with respect to pain should be dropped. Clin J Pain. 2000; 16:365. [PubMed: 11153795]

64. International Association for the Study of Pain. Classification of chronic pain. Pain. 1986; 24:S1.

65. Wolfe F, Smythe HA, Yunus MB, et al. The American College of Rheumatology 1990 Criteria for the Classification of Fibromyalgia. Report of the Multicenter Criteria Committee. Arthritis Rheum. 1990; 33:160. [PubMed: 2306288]

66. America Psychiatric Association (APA). Diagnostic and Statistical Manual of Mental Disorders. 4. Washington: APA; 1994. (DSM-IV) 
Table 1

Characteristics of 1521 HIV-Infected Patients Seen for Outpatient Medical Care at the UAB HIV Clinic, April 2008-June 2011

\begin{tabular}{|c|c|}
\hline Characteristic & Sample $(\mathrm{N}=1521)$ \\
\hline Age, years & $43.7(36.0-50.0)$ \\
\hline \multicolumn{2}{|l|}{ Sex $\times$ race/ethnicity } \\
\hline Non-white female & $244(16.1 \%)$ \\
\hline Non-white male & $548(36.2 \%)$ \\
\hline White female & $96(6.4 \%)$ \\
\hline White male & $624(41.3 \%)$ \\
\hline \multicolumn{2}{|l|}{ Health Insurance } \\
\hline Uninsured & $468(30.9 \%)$ \\
\hline Public & $454(29.9 \%)$ \\
\hline Private & $594(39.2 \%)$ \\
\hline CD4+ T-lymphocyte count (cells $/ \mathrm{mL}$ ) & $445(270-648)$ \\
\hline$<200$ cells $/ \mathrm{mL}$ & $259(17.1 \%)$ \\
\hline $200-350$ cells $/ \mathrm{mL}$ & $289(19.1 \%)$ \\
\hline$>350$ cells $/ \mathrm{mL}$ & $963(63.7 \%)$ \\
\hline \multicolumn{2}{|l|}{ HIV transmission risk factor } \\
\hline Injection drug use & $141(9.3 \%)$ \\
\hline Men who have sex with men & $835(54.9 \%)$ \\
\hline Other/unknown & $15(1.0 \%)$ \\
\hline Heterosexual & $530(34.9 \%)$ \\
\hline Pain & $509(33.9 \%)$ \\
\hline Mood & $383(25.2 \%)$ \\
\hline Substance abuse & $153(10.1 \%)$ \\
\hline \multicolumn{2}{|l|}{ Pain-Mood-Substance categories } \\
\hline Only pain & $239(16.0 \%)$ \\
\hline Only mood & $115(7.7 \%)$ \\
\hline Only substance abuse & $47(3.2 \%)$ \\
\hline Pain and mood & $189(12.7 \%)$ \\
\hline Pain and substance & $30(2.0 \%)$ \\
\hline Mood and substance & $24(1.6 \%)$ \\
\hline Pain, mood, and substance & $46(3.1 \%)$ \\
\hline None & $800(53.7 \%)$ \\
\hline \multicolumn{2}{|l|}{ Outcome Variables } \\
\hline$\geq 1$ no-show visit & $624(41.0 \%)$ \\
\hline$\geq 1$ urgent visit & $390(25.6 \%)$ \\
\hline Skip ART past 2 weeks (adherence) & $220(19.0 \%)$ \\
\hline HIV RNA $\geq 200$ copies $/ \mathrm{ml}$ & $309(37.2 \%)$ \\
\hline
\end{tabular}

J Acquir Immune Defic Syndr. Author manuscript; available in PMC 2013 October 01. 
Data is presented as medians and interquartile ranges or frequencies (column percent). Age and health insurance measured at the index visit. HIV RNA and CD4+ T-lymphocyte count measurements were the value closest to the index visit, with a window of -210 to +14 days. No-show and urgent visits measured over 1 year period following index visit

Missing data: race/sex 9, insurance status 5, CD4+ T-lymphocyte count 10, pain 21, substance abuse 11, adherence 10 (plus 353 not on ART), HIV RNA $\geq 200$ copies/mL 18 (plus 353 not on ART).

UAB: University of Alabama at Birmingham. 
Table 2

No-Show Visits

\begin{tabular}{|c|c|c|}
\hline Characteristic & Unadjusted OR (95\% CI) & Adjusted OR (95\% CI) \\
\hline Pain & $1.4(1.1-1.8)$ & \\
\hline With substance abuse ${ }^{*}$ & & $0.5(0.2-0.9)$ \\
\hline Without substance abuse ${ }^{\dagger}$ & & $1.5(1.1-1.9)$ \\
\hline Mood disorder & $1.5(1.2-1.9)$ & $1.3(1.0-1.7)$ \\
\hline Substance abuse & $2.0(1.4-2.8)$ & \\
\hline With pain $t$ & & $0.9(0.6-1.6)$ \\
\hline Without pain $\xi$ & & $3.1(1.8-5.3)$ \\
\hline Age (per 10 years) & $0.7(0.6-0.8)$ & $0.7(0.6-0.8)$ \\
\hline \multicolumn{3}{|l|}{ Sex and Race/Ethnicity } \\
\hline Non-White Female & $2.4(1.7-3.2)$ & $2.4(1.6-3.7)$ \\
\hline Non-White Male & $2.6(2.1-3.3)$ & $2.2(1.7-2.9)$ \\
\hline White Female & $2.0(1.3-3.2)$ & $1.8(1.0-3.1)$ \\
\hline White Male & 1.0 & 1.0 \\
\hline \multicolumn{3}{|l|}{ Health Insurance } \\
\hline None & $2.5(1.9-3.2)$ & $1.6(1.2-2.1)$ \\
\hline Public & $2.5(1.9-3.2)$ & $2.0(1.5-2.7)$ \\
\hline Private & 1.0 & 1.0 \\
\hline \multicolumn{3}{|c|}{ Baseline CD4+ T lymphocyte count (cells/mL) } \\
\hline$<200$ cells/mL & $2.2(1.7-2.9)$ & $1.7(1.2-2.3)$ \\
\hline $200-350$ cells $/ \mathrm{mL}$ & $1.6(1.2-2.1)$ & $1.6(1.2-2.1)$ \\
\hline$>350$ cells $/ \mathrm{mL}$ & 1.0 & 1.0 \\
\hline \multicolumn{3}{|l|}{ HIV Transmission Risk factor } \\
\hline Intravenous Drug Use & $1.2(0.8-1.7)$ & $1.3(0.9-2.1)$ \\
\hline Men who have sex with men & $0.7(0.6-0.9)$ & $1.0(0.7-1.4)$ \\
\hline Other/unknown & $5.0(1.4-17.9)$ & $2.6(0.7-9.8)$ \\
\hline Heterosexual & 1.0 & 1.0 \\
\hline
\end{tabular}

Event $=$ At least one HIV primary care no-show visit during the year following the index visit. Bolded results are statistically significant. Adjusted model contains all variables shown in the table

* $\mathrm{N}=76 / 147=51.7 \%$ (among participants with substance abuse, proportion with pain)

${ }^{\dagger} \mathrm{N}=428 / 1343=31.9 \%$ (among participants without substance abuse, proportion with pain)

${ }^{\dagger} \mathrm{N}=76 / 504=15.1 \%$ (among participants with pain, proportion with substance abuse)

$\mathcal{S}=71 / 986=7.2 \%$ (among participants without pain, proportion with substance abuse) 
Table 3

Urgent visit utilization

\begin{tabular}{|c|c|c|}
\hline Characteristic & Unadjusted OR (95\% CI) & Adjusted OR (95\% CI) \\
\hline Pain & $1.6(1.2-2.0)$ & $1.3(1.0-1.7)$ \\
\hline Mood disorder & $1.8(1.4-2.4)$ & $1.6(1.2-2.2)$ \\
\hline Substance abuse & $1.4(1.0-2.0)$ & $1.1(0.7-1.6)$ \\
\hline Age (per 10 years) & $1.0(0.9-1.1)$ & $1.0(0.8-1.1)$ \\
\hline \multicolumn{3}{|l|}{ Sex and Race/Ethnicity } \\
\hline Non-White Female & $1.2(0.8-1.6)$ & $1.4(0.9-2.1)$ \\
\hline Non-White Male & $0.9(0.7-1.1)$ & $0.9(0.7-1.3)$ \\
\hline White Female & $1.0(0.6-1.6)$ & $0.8(0.5-1.5)$ \\
\hline White Male & 1.0 & 1.0 \\
\hline \multicolumn{3}{|l|}{ Health Insurance } \\
\hline None & $1.4(1.0-1.8)$ & $1.2(0.9-1.7)$ \\
\hline Public & $1.6(1.2-2.2)$ & $1.4(1.0-1.9)$ \\
\hline Private & 1.0 & 1.0 \\
\hline \multicolumn{3}{|c|}{ Baseline CD4+ T lymphocyte count (cells/mL) } \\
\hline$<200$ cells $/ \mathrm{mL}$ & $1.4(1.0-1.9)$ & $1.3(1.0-1.8)$ \\
\hline $200-350$ cells $/ \mathrm{mL}$ & $1.6(1.2-2.2)$ & $1.7(1.2-2.3)$ \\
\hline$>350$ cells $/ \mathrm{mL}$ & 1.0 & 1.0 \\
\hline \multicolumn{3}{|l|}{ HIV Transmission Risk factor } \\
\hline Intravenous Drug Use & $1.7(1.1-2.5)$ & $1.5(0.9-2.4)$ \\
\hline Men who have sex with men & $1.0(0.8-1.3)$ & $1.1(0.7-1.5)$ \\
\hline Other/unknown & $0.2(0.03-1.7)$ & $0.2(0.02-1.3)$ \\
\hline Heterosexual & & \\
\hline
\end{tabular}

Event $=$ At least one urgent visit during the year following the index visit. Bolded results are statistically significant. Adjusted model contains all variables shown in the table 
Table 4

Adherence to Antiretroviral Therapy

\begin{tabular}{|c|c|c|}
\hline Characteristic & Unadjusted OR (95\% CI) & Adjusted OR (95\% CI) \\
\hline Pain & $1.4(1.1-1.9)$ & $1.2(0.8-1.7)$ \\
\hline Mood disorder & $2.1(1.6-2.9)$ & $2.2(1.5-3.2)$ \\
\hline Substance abuse & $3.1(2.0-4.8)$ & $2.8(1.7-4.6)$ \\
\hline Age (per 10 years) & $0.9(0.8-1.0)$ & $0.9(0.8-1.1)$ \\
\hline \multicolumn{3}{|l|}{ Sex and Race/Ethnicity } \\
\hline Non-White Female & $2.3(1.5-3.5)$ & $2.4(1.4-4.3)$ \\
\hline Non-White Male & $1.7(1.2-2.4)$ & $1.9(1.3-2.8)$ \\
\hline White Female & $0.3(0.1-1.0)$ & $0.3(0.1-1.0)$ \\
\hline White Male & 1.0 & 1.0 \\
\hline \multicolumn{3}{|l|}{ Health Insurance } \\
\hline None & $1.3(0.9-1.8)$ & $1.0(0.7-1.5)$ \\
\hline Public & $1.1(0.8-1.6)$ & $0.9(0.6-1.3)$ \\
\hline Private & 1.0 & 1.0 \\
\hline \multicolumn{3}{|c|}{ Baseline CD4+ T lymphocyte count (cells/mL) } \\
\hline$<200$ cells $/ \mathrm{mL}$ & $1.4(1.0-2.1)$ & $1.1(0.7-1.6)$ \\
\hline $200-350$ cells $/ \mathrm{mL}$ & $1.0(0.7-1.5)$ & $1.0(0.7-1.5)$ \\
\hline$>350$ cells $/ \mathrm{mL}$ & 1.0 & 1.0 \\
\hline \multicolumn{3}{|l|}{ HIV Transmission Risk factor } \\
\hline Intravenous Drug Use & $0.6(0.3-1.0)$ & $0.6(0.3-1.1)$ \\
\hline Men who have sex with men & $0.8(0.6-1.1)$ & $0.9(0.5-1.4)$ \\
\hline Other/unknown & $0.7(0.2-3.3)$ & $0.4(0.1-2.0)$ \\
\hline Heterosexual & 1.0 & 1.0 \\
\hline
\end{tabular}

Event $=$ suboptimal adherence to ART (missed dose within past 2 weeks) at the index visit. Bolded results are statistically significant. Adjusted model contains all variables shown in the table.

Models are based on the subset of patients who reported being on ART $(\mathrm{N}=1168)$ 
Table 5

Virologic Failure

\begin{tabular}{|c|c|c|}
\hline Characteristic & Unadjusted OR (95\% CI) & Adjusted OR (95\% CI) \\
\hline Pain & $1.2(0.9-1.5)$ & $1.1(0.8-1.5)$ \\
\hline Mood disorder & $1.2(0.9-1.7)$ & $1.1(0.8-1.6)$ \\
\hline Substance abuse & $1.4(0.9-2.1)$ & $1.1(0.7-1.8)$ \\
\hline Age (per 10 years) & $0.9(0.8-1.0)$ & $0.9(0.8-1.1)$ \\
\hline \multicolumn{3}{|l|}{ Sex and Race/Ethnicity } \\
\hline Non-White Female & $1.0(0.7-1.6)$ & $1.2(0.7-2.0)$ \\
\hline Non-White Male & $1.6(1.2-2.2)$ & $1.4(1.0-2.0)$ \\
\hline White Female & $0.9(0.5-1.7)$ & $1.0(0.5-2.0)$ \\
\hline White Male & 1.0 & 1.0 \\
\hline \multicolumn{3}{|l|}{ Health Insurance } \\
\hline None & $1.2(0.9-1.7)$ & $0.9(0.6-1.2)$ \\
\hline Public & $1.3(1.0-1.8)$ & $1.1(0.8-1.5)$ \\
\hline Private & 1.0 & 1.0 \\
\hline \multicolumn{3}{|c|}{ Baseline CD4+ T lymphocyte count (cells/mL) } \\
\hline$<200$ cells $/ \mathrm{mL}$ & $3.7(2.6-5.2)$ & $3.3(2.3-4.8)$ \\
\hline $200-350$ cells $/ \mathrm{mL}$ & $1.8(1.3-2.5)$ & $1.8(1.3-2.5)$ \\
\hline$>350$ cells $/ \mathrm{mL}$ & 1.0 & 1.0 \\
\hline \multicolumn{3}{|l|}{ HIV Transmission Risk factor } \\
\hline Intravenous Drug Use & $0.8(0.5-1.4)$ & $0.9(0.5-1.6)$ \\
\hline Men who have sex with men & $1.0(0.8-1.4)$ & $1.1(0.8-1.7)$ \\
\hline Other/unknown & $2.7(0.9-8.6)$ & $1.9(0.5-6.3)$ \\
\hline Heterosexual & 1.0 & 1.0 \\
\hline
\end{tabular}

Event $=$ Failure to suppress virus $(\mathrm{VL} \geq 200)$ at the index visit. Bolded results are statistically significant. Adjusted model contains all variables shown in the table.

Models are based on the subset of patients who reported being on ART ( $\mathrm{N}=1168)$ 